\title{
LA ANOREXIA: CUANDO LA MUERTE NO EXISTE
}

\author{
Teresa Sunyé i Barcons ${ }^{1}$ \\ Centre de Psicologia Clínica i Psicoterapia. Terrassa. Barcelona
}

Una de las mayores dificultades que se presentan en el curso del tratamiento de las personas anoréxicas consiste en su problemática relación con la alimentación, hecho que les puede conducir a estados graves de inanición cercanos a la muerte e incluso a morir. No se trata de que las anoréxicas busquen su propia muerte, sino más bien pretenden la desaparición de su propio cuerpo del que tratan de desprenderse a cualquier precio. En realidad, el rechazo a alimentarse es la "solución" que han encontrado en un intento desesperado de sobrevivir a la perturbación emocional contra la que luchan sin cesar. Únicamente desprendiéndose de su cuerpo sienten que es posible librarse de una presencia que les invade y de una subjetividad preñada de un vacio insondable que ha surgido en la relación con este Otro. En este sentido, podemos entender la anorexia como una lucha por el amor, por la propia vida, para ser, para existir como seres singulares y únicos, como personas queridas en su individualidad y características propias.

Palabras clave: Alimento, anorexia, cuerpo, muerte, síntoma.

One of the greatest difficulties that arise in the course of treatment of people suffering from anorexia is their problematic relationship with food, a fact that can lead to severe starvation, near death and even death. It is not that they seek their own death, but rather seek the disappearance of their own body which they try to get rid of at any price. In reality, the refusal to take food is the "solution" they have found in a desperate attempt to survive the emotional disturbance they constantly struggle against. Only by detaching themselves from their body do they feel that it is possible to get rid of a presence that invades them and of a subjectivity pregnant with an unfathomable void that has arisen in the relationship with this Other. In this sense, we can understand anorexia, as a struggle for love, for one's own life, to be, to exist as a human being.

Key Words: Food, anorexia, body, death, symptom

\section{English Title: ANOREXIA: WHEN DEATH DOES NOT EXIST}

\section{Cita bibliográfica / Reference citation:}

Sunyé i Barcons, Teresa (2019). La anorexia: cuando la muerte no existe. Clínica e Investigación Relacional, 13 (2): 422-440. [ISSN 1988-2939] [Recuperado de www.ceir.info ] DOI: $10.21110 / 19882939.2019 .130207$

\footnotetext{
${ }^{1}$ Psicóloga clínica. Psicoterapeuta. Psicoanalista relacional. Diplomada en Estudis Avançats (DEA) en Problemas de filosofía contemporánea por la Universitat de Barcelona. Specialist Certificate in Psychotherapy y European Certificate in Psychology por l'European Federation of Psychologists' Associations (EFPA). Psicoterapeuta reconocida por la FEAP. Ex docente del Màster en Sostenibilitat i Humanisme y de la Càtedra UNESCO de la Universitat Politècnica de Catalunya. Miembro del Instituto de Psicoterapia Relacional (IPR), de la Acadèmia de Ciències Mèdiques i de la Salut de Catalunya i de Balears, de la Societat Catalano Balear de Psicologia (ACMCB). Activitad como psicoterapeuta de adultos/adolescentes en el Centre de Psicologia clínica i Psicoterapia (Terrassa). Gestión y dirección del ciclo de conferencias Espai de Paraula (Terrassa). Autora de diversos artículos científicos. Coautora del manual Pediatría en atención primaria (2013) y del libro Las experiencias terapéuticas en el proceso psicoanalítico (2017). Contacto: teresasunye@comb.cat y www.teresasunye.com
} 
Este artículo sobre la anorexia es fruto del trabajo con mujeres y muchachas jóvenes que sufrían, y algunas de ellas todavía lo padecen, el problema de la anorexia. El hecho de acompañarlas en su proceso, establecer un vínculo terapéutico con ellas, inventando recursos en los momentos que sentíamos paralizadores.... me enriqueció en la comprensión, no únicamente de algunos mecanismos y características de la anorexia, sino también en un mayor entendimiento de unos padecimientos lacerantes y en la admiración hacia estas pacientes en su lucha, en sus esfuerzos, en su caer y levantarse de nuevo con la ilusión y la esperanza de poder vivir una vida sin tanto sufrimiento.

Una de las mayores dificultades que se presentan en el curso del tratamiento de las personas anoréxicas consiste en su problemática relación con la alimentación, hecho que les puede conducir a estados graves de inanición cercanos a la muerte e incluso a morir. No se trata de que las anoréxicas busquen su propia muerte, sino más bien de la desaparición de esa carne que ellas sienten odiosa y de la que tratan de desprenderse a cualquier precio. En realidad, este desasirse de su propia carne es la "solución" que han encontrado en un intento desesperado de sobrevivir a la perturbación emocional contra la que luchan sin cesar. Ellas no sienten la posibilidad de morir si no se alimentan, es negada, disociada en una zona oscura de su mente, en un intento vitalmente necesario para sobrevivir a la devastación del Otro. Únicamente desapareciendo es posible librarse de la presencia invasora y de una subjetividad preñada de un vacío insondable que ha surgido en la relación con este Otro. En este sentido la anorexia la podemos entender como una lucha por el amor, por la propia vida, para ser, para existir como seres singulares y únicos, como personas queridas en su individualidad y características propias.

\section{Etimología de la palabra anorexia}

El conocimiento de esta perturbación viene de lejos y la encontramos en los antiguos textos de la medicina hipocrática. Etimológicamente la palabra anorexia significa: alcanzar, tocar, tender, ofrecer, extenderse, dar, desear a alguien.... No tiene la connotación de comer, pero si la de desear. Procede del griego $\alpha \nu o \rho \varepsilon \xi ı$ (anorexia) compuesta por el prefijo griego

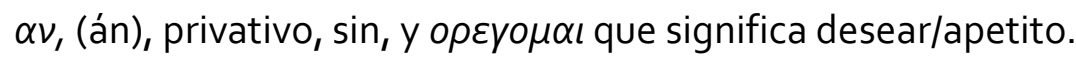

\section{Abstinencia}

En la antigüedad la abstinencia formaba parte de la práctica religiosa en general y su motivación inmediata variaba en los distintos casos. Hasta finales del siglo III (d. C.) y 
principios del IV (d.C.) no se estableció el ayuno como práctica religiosa relevante, definitoria de la comunidad cristiana e identificada con la pureza del corazón ante Dios.

En el siglo IV (d. C.) la religión cristiana alcanzó un estatus oficial en el imperio romano. No deja de ser interesante la forma como el ayuno adquirió de una manera notoria un cierto papel contestatario, que mucho tiempo después encontramos de nuevo en la anorexia. Según entendían algunos, progresivamente la iglesia cristiana se relajó y perdió parte de su ímpetu primitivo, aquel que mantuvo durante los siglos de martirios y persecuciones. Los ayunadores de aquella época se hicieron, en muchos casos, depositarios de las virtudes primitivas y el ascetismo se convirtió en un sustituto apropiado del martirio. Es conocido el gesto de la santa Wilgerfortis (virgen fuerte) quien, en el siglo $X$, se negó a comer hasta morir para evitar su matrimonio con un hombre que le inspiraba un profundo menosprecio.

En la Edad Media la carne debía ser dominada. El espíritu tenía que triunfar. El ayuno era un medio idóneo para conseguirlo. Mantenerse sin comer era considerado como un signo de santidad. A pesar de todo, ello no era juzgado siempre de esta manera. En efecto, no era infrecuente que se catalogara a la persona como alguien que sufría una enfermedad o algún tipo de limitación. Santa Catalina de Siena, por ejemplo, cuando se encontraba en plena inanición pensaba que estaba sufriendo una enfermedad y no que estuviera llevando a término una práctica de ascesis religiosa.

En los inicios de la era Moderna la santidad ejemplar del ayuno de los primeros años del cristianismo, después puesta en duda por las reticencias eclesiásticas, que veían en esta práctica una inquietante disolución de sus preceptos colectivos, se transformó en su contrario, llegándose a ser condenada como propia de una influencia demoníaca. Los endemoniados podían subsistir mucho tiempo sin alimentos, según se creía, porque el maligno se encargaba de nutrirlos.

Desde el siglo XVI hasta el siglo XIX fueron muchas las mujeres, denominadas "mujeres ayunadoras" que restringían dramáticamente su alimentación, con lo cual conseguían una gran atención pública y frecuentes recompensas materiales. En su mayoría, se trataba de mujeres jóvenes y de procedencia humilde; por descontado se mantenían solteras, de forma que su rechazo de los alimentos resaltaba todavía más lo sublime y puro de su virginidad.

Especialmente durante los siglos del XV al XVIII las mujeres ayunadoras corrían con frecuencia el riesgo de ser consideradas como brujas o como poseídas por Satanás. En la imaginación popular las brujas, dado su condición de mujeres voladoras, necesitaban ser muy ligeras de peso. Era lógico, pues, que la bruja más o menos vocacional perdiera peso. De hecho, en el Malleus Maleficarum (El Martillo de los Brujos), escrito el 1486 por dos 
monjes dominicos, se convirtió a lo largo de tres siglos en el manual indispensable y la autoridad final para la Inquisición en la lucha contra la brujería en Europa. Una de las pruebas para detectar que una mujer era bruja era comprobar si el peso corporal de la sospechosa se hallaba por debajo de lo esperado en función de su estatura.

En pleno siglo XIX un hombre muy pintoresco, Claude Ambroise Saurat, conocido como el "Hombre Anatómico", se constituyó en el prototipo de los denominados "artistas del hambre" o "esqueletos vivientes". En principio, se trataba de hombres que exhibían su especial habilidad para seguir con vida pese a no comer en absoluto durante ciertos periodos de tiempo. Principalmente se exhibían en ferias, aunque en las primeras décadas del siglo XX todavía podían verse algunos de ellos en cafés y cabarets. Kafka en su libro $E l$ artista hambriento (1924) describe detalladamente la experiencia subjetiva de uno de estos hombres.

Es tan solo a partir del último cuarto del siglo XIX que la anorexia se considera un estado patológico, pero hasta entonces la concepción de la misma pasó por diversas alternativas, de acuerdo con el espíritu de la época. Primeramente, implicó una connotación de santidad, después una posible posesión demoniaca, más tarde una magia o una posible simulación, para acabar siendo el tema reservado para una medicina más o menos psicologizada. La oralidad y sus conflictos tienen, por cierto, diferentes modos de expresión. La trayectoria reconocida es, por tanto: santo/a-demonio/a-enfermo/a.

Sabemos ahora que el ayuno prolongado conduce, a través de alteraciones metabólicas, a modificaciones del funcionamiento mental; es decir, se produce una alteración de la consciencia del cuerpo. Al quebrantar las leyes de la biología, puede producirse en la persona el sentimiento de aproximación a lo trascendente, del triunfo sobre la materia/cárcel (Caparrós y Sanfeliu, 1977). Ello parece ser debido a que, tal como se ha comprobado, la autofagia de los músculos propios da lugar a la producción de sustancias como la dopamina, la noradrenalina y la endorfina, que son neurotransmisores estimulantes y euforizantes. Es decir, la pérdida de la propia carne puede llegar a ser adictiva. Por ejemplo, Tomas de Aquino advirtió respecto a los peligros del ayuno debido a lo que él llamó la renovación de los sentidos, que se produce como resultado de la deprivación sensorial. Según él, por medio de las prácticas ascéticas, los sentidos quedan desprovistos de sus condicionamientos y se experimentan de forma diferente las experiencias corporales.

La anorexia apareció como entidad clínica en el siglo XVII en el libro Tratado de las Consumiciones de Richard Morton en 1694. Es el primer autor que se refirió con precisión al cuadro clínico de la anorexia diferenciándolo de otras alteraciones. En 1774, Djerine, señaló 
que el rechazo de alimentos tiene un origen psíquico, y lo describió decididamente como una entidad separada de otros trastornos orgánicos. Tal entidad es la que más adelante ha sido conocida como anorexia mental.

En los inicios del siglo XIX comenzaron a gestarse las bases de las concepciones actuales acerca de la anorexia. Su estudio detallado se inició principalmente en Francia a partir de Charles Lasègue y en Inglaterra por medio de William Gull. Debido a ambos la anorexia dejó definitivamente de ser un asunto divino o demoníaco, también de ser una farsa y entró en la ciencia médica desde el ámbito de lo psíquico.

\section{Aspectos sociales}

Fue a finales de la década de los ochenta y, principalmente, a partir de la década de los noventa, cuando empezó a darse un incremento considerable de la incidencia de la anorexia, lo que dio lugar a que llegara a ser considerada una epidemia. Una epidemia impulsada por características sociales y culturales de la sociedad posmoderna, pero en la que también intervienen causas familiares y factores que pertenecen a la singularidad del individuo.

Por un lado, hemos visto la manera como el síntoma, en este caso el rechazo del alimento, puede recibir connotaciones muy diversas dependiendo del momento cultural, histórico y religioso en el que vive la afectada, ya sea santa, endemoniada o simplemente enferma. Por otra parte, el malestar psíquico se reviste siempre de unas características sintomáticas vinculadas al momento histórico. En la actualidad el alimento y el comer se han convertido en el centro de nuestras vidas. Según Janette Treasure (2007), psiquiatra que investiga los trastornos alimentarios, si el sexo era la obsesión del siglo XIX, la de este siglo es la comida. Antes el cuerpo pedía sexo y la moral reprimía este deseo... En el presente, la medicina y la moda condenan la obesidad, pero la industria la fomenta al enunciar y ofrecer alimentos extra-calóricos en todo momento y en todo lugar. Nunca comer ha sido tan pecaminoso y, al mismo tiempo, tan difícil no comer. Pese a que, desafortunadamente, para tantos sujetos económicamente desfavorecidos conseguir alimento es una lucha diaria.

Una sociedad occidental actual globalizada en continuo movimiento y vertiginoso cambio, en la que los valores humanos quedan a menudo desbancados por el culto al dinero y el consumo es la moneda de prestigio social, en la que la tecnología domina y tiraniza los rincones más íntimos de los seres humanos, en la que los ideales sociales, religiosos y políticos, que a menudo sirven para dar sentido y coherencia a las trayectorias vitales, 
quedan frecuentemente arrinconadas por motivos diversos, todo ello dificulta el proceso psíquico de contención y encauzamiento del sufrimiento psíquico.

En un momento histórico como el actual, en el que la imagen corporal toma una relevancia desconocida en épocas anteriores, en la que se condensa el ser del individuo y en el que dicha imagen se ha convertido en la primera y privilegiada presentación de la persona; en el que los dictados de la belleza toman unas dimensiones globales impulsadas por los medios tecnológicos, el cuerpo se torna el único lugar a partir del cual el sujeto puede servirse como punto de anclaje en su búsqueda de la identidad y, al mismo tiempo deviene el receptáculo que recoge el malestar psíquico de muchos hombres y mujeres. Se busca en la restricción del alimento un estado de bienestar psíquico a través del reconocimiento interpersonal de la belleza de los cuerpos, belleza que, por otra parte, parece ser equivalente a la delgadez.

\section{Diagnóstico}

No siempre podemos diagnosticar como anorexia el rechazo de alimento. Se presenta una negación a alimentarse en muchas patologías mayores tales como la melancolía, en la que predomina una carencia absoluta de apetito. En algunos casos de trastornos de ansiedad se presentan síntomas de restricción alimentaria; también en cuadros de psicosis esquizofrénica, especialmente en los estados catatónicos; asimismo puede aparecer en la paranoia debido al temor al envenenamiento $y$, en todas ellas, la relación del sujeto con el alimento tiene una especial relevancia sin que pueda hablarse siempre de anorexia.

La revisión de la literatura pone de manifiesto la diversidad psicopatológica que se considera subyacente al síndrome de la anorexia, a partir de lo que es característico de este estado: patología narcisista (Winnicott, 1974; Geist, 1989; Mc Dougall, 1991); depresión (Alessi y col., 1989; Walters y Kendler, 1995); trastorno obsesivo-compulsivo (Thiel y col., 1995); trastorno de ansiedad generalizada y crisis de pánico (Walters y Kendler, 1995); alexitimia (Zonis de Zukerfeld, 1996) y dificultades en el proceso de separaciónindividualización (Friedlander y Siege, 1999).

Personalmente siento mi experiencia y comprensión de la anorexia muy cercana a la expresada por Doménico Cosenza en su libro El Muro de la Anorexia (2008), en el que sostiene que en el corazón de quien padece anorexia ha existido, en algún momento, un rechazo fundamental, una negación a nivel muy íntimo de su subjetividad, de su vivencia de sí mismo, no consciente por la persona que padece ese trastorno. La persona anoréxica no solo rechaza el alimento, sino lo que la comida significa para ella: el cuerpo como 
posibilidad de desear, de demandar, de establecer vínculos amorosos, de dependencia hacia otros, de necesitarlos... puesto que tal persona se ha sentido profunda e íntimamente rechazada y, además, no ha experimentado que le haya sido dado un espacio propio en el que poder desarrollar su subjetividad y su singularidad como sujeto. La forma que ha encontrado para hacer frente a este rechazo es rechazar ella su propio cuerpo, y junto con él, la intimidad con el otro, su relación cercana, sus palabras, su comida.

\section{Existir}

Según Sartre (1943) yo existo cuando el otro me mira, y Lacan (1949) formula, en el estadio del espejo, la necesidad de otro que nos mire viéndonos, como condición necesaria para que tengamos la vivencia de existir. Joan Coderch (2018) se refiere en repetidas ocasiones sobre la naturaleza esencialmente relacional de los seres humanos. Los humanos somos seres de relación, nos constituimos en relación con los otros. Es mediante el reconocimiento del otro en estas relaciones primeras que las personas adquirimos la propia vivencia del self, de individuos.

A muchas anoréxicas les ha faltado este reconocimiento de ser una persona diferente, con deseos, sensaciones, gustos, anhelos y aspiraciones propias. A menudo, muchas de ellas se han sentido vividas como una prolongación de la madre, consideradas como una parte de ella, y han experimentado una invasión dolorosa de su subjetividad, cosa que les ha comportado una dificultad para desplegar una subjetividad propia, debido a la falta de un espacio vital que no les ha sido otorgado. Una madre que no ha dejado lugar para un tercero, o un tercero que no ha existido o, en todo caso, ha existido muy escasamente para el niño. La falta de reconocimiento emocional que vive el niño también se produce si ha tenido vivido una desvinculación de la madre, o persona que ejerza su función, respecto al infante, creando en él una vivencia abismal de soledad y desamparo.

También encontramos a menudo, en los casos de anorexia, padres con poca o nula capacidad para estar presentes, ya sea por su propio desinterés, o bien como consecuencia de una actitud de la madre que les inhabilita en su papel respecto al hijo/a, lo que comporta, en ambos casos, una escasa presencia afectiva de la figura paterna en la vida familiar. Todos los seres humanos hemos vivido una relación de profunda dependencia en nuestros primeros años, puesto que ésta es la única manera de sobrevivir y, a la vez, de convertirnos en individuos autónomos. En tal relación de dependencia el infante va encontrando sus signos de identidad, sus gustos, necesidades y anhelos, los cuales, al ser reconocidos por la madre y validados por el padre le permiten ir construyendo una identidad propia distinta de la de sus progenitores. Pero al mismo tiempo recordar que una función específica del 
padre, o persona que ejerza su función, es la de ayudar al niña/o, a través de su intercambio emocional, a distanciarse de la madre para conseguir formar su propio self individualizado.

Si la madre, o figura sustitutiva, no puede reconocer al infante como un ser suficientemente diferenciado de ella, con deseos, gustos, aspiraciones y necesidades distintas a las suyas, el niño se siente absorbido y devorado emocionalmente por una madre que, en estos casos, no le permite construir un espacio mental propio, o bien se vive como ignorado o desvalido. Es posible que este no reconocimiento por parte de la madre sea la expresión de dificultades diversas en la integración de la figura paterna en la diada madre hijo/a. La consecuencia es que el infante no puede desarrollar un sentimiento de ser un ente individual y diferenciado frente a otro ser individual, no puede construir una identidad personal ni sentir su cuerpo como propio. Aunque siempre es difícil para el niño o niña articular la separación con el otro materno, si en la relación primera se ha sentido absorbido o ignorado por éste, la separación entre él/ella y la figura materna se convierte en una ardua y complicada tarea.

La experiencia de separación del otro materno no concierne solamente a la fase del destete, sino que supone la separación de una parte de sí mismo/a. Durante las primeras experiencias el infante no percibe una diferencia entre el pecho de la madre y él mismo. Posteriormente, para su sano desarrollo, el infante debe articular una operación de separación entre ambos, la cual vive como si perdiera una parte de sí mismo. El problema es que esta separación, por su complejidad, no siempre se resuelve de forma satisfactoria, cosa que constatamos en la clínica de la anorexia. En la mayoría de los casos en los que no se ha podido establecer un vínculo saludable de reconocimiento emocional del bebé por parte de la madre, éste no acepta perder la parte suya que se encuentra en el cuerpo materno, y, en lugar de evolucionar en dirección a la separación emocional, queda atrapado en el primer objeto. Cuando sucede esto el niño o niña encontrarán, durante el recorrido de su existencia, una dificultad extrema en situaciones contingentes de la vida en las que sucesos vitales que tienen relación con pérdidas $u$ otros acontecimientos traumáticos les resultarán sumamente difíciles de elaborar.

Cada vez que alguna de estas situaciones se presenta en la existencia de la persona, las dificultades y problemáticas emocionales que aparecen son un reflejo de las dificultades vividas por el sujeto en el proceso de la separación del primer objeto. Es especialmente significativo, para el caso que nos ocupa, la forma como estos conflictos que reaparecen en la pubertad conduce, en muchos casos, a desarrollar síntomas de trastorno emocional, tal como pueden ser los propios de la anorexia. Si el sujeto no ha podido elaborar un proceso de separación del objeto materno de manera suficientemente satisfactoria, con la llegada 
de la pubertad, durante la cual las transformaciones del propio cuerpo provocan en el adolescente una pérdida de sus referencias corporales, con la consiguiente y necesaria asimilación de una nueva imagen corporal, el surgimiento de nuevos comportamientos, actitudes y vivencias en las relaciones con los padres y, en general con el entorno, a la vez que desarrolla nuevos planteamientos respecto a su futuro, el adolescente carenciado de elementos emocionales para construir puentes emocionales con los que atravesar esta etapa vivencial, tendrá dificultades para asumir este complejo cambio físico, vivencial y relacional al que se enfrenta, y para resolver estas dificultades el sujeto se inventa una respuesta que, en muchos casos, especialmente en las chicas, es la anorexia. Al no poder asimilar el surgimiento con fuerza de la sexualidad que se despierta en la adolescente, ésta retrocede ante su empuje, mediante el síntoma de la anorexia. No es casualidad, por tanto, que la repercusión de la anorexia se muestre en el cuerpo en forma de un retroceso, de una cancelación a todos los efectos de transformación del cuerpo como, por ejemplo, los caracteres sexuales secundarios y, en la mayoría de los casos, del ciclo menstrual.

\section{6.- Síntoma}

Anteriormente hemos visto como las explicaciones sobre las causas de la anorexia desde el punto de vista psicológico son muy variadas, pero también lo son las teorías que se formulan sobre esta patología desde muy diversas disciplinas, ya sean médicas o estéticas, pasando por las sociológicas. Ello evidencia la complejidad de esta patología y la dificultad de encontrar respuestas que la definan en su complejidad. Por todo ello se hace evidente la necesidad de escuchar la palabra individual de la persona que padece este trastorno. Es pues, tan solo teniendo en cuenta su palabra, su presencia, sus silencios, sus ausencias a veces de las sesiones, sus alegrías y sufrimientos que podemos empezar a entender y participar de la experiencia que tiene ella de sí misma, de su relación con los demás y con el mundo.

La restricción de la alimentación no es sino la punta del iceberg de un sufrimiento que encuentra en el control de la alimentación su forma de expresarse. Un sufrimiento que resulta del esfuerzo titánico que realiza la persona anoréxica para encontrar un lugar en el mundo desde donde poder vivir, de un intento desesperado para calmar el dolor en su búsqueda de una subjetividad que no encuentra.

En la anorexia no hemos de pretender como objetivo solamente eliminar rápidamente el síntoma. La anorexia representa para el sujeto una "solución", aunque patológica, a un malestar insoportable. La prioridad en estos casos es lograr que el sujeto pueda expresar verbalmente, o de otras formas simbólicas, su malestar, otorgarle la palabra acerca de este 
sufrimiento del cual el mismo ignora el origen. Ello se convierte en una tarea ardua y dificultosa porque, en la primera fase del tratamiento, la anoréxica experimenta una verdadera "luna de miel" con su propio síntoma, como el toxicómano con la droga, del cual no quiere desprenderse de ninguna forma. Será tan solo cuando consiga salir de esta "luna de miel", que le será posible sentir que el síntoma agrava su sufrimiento y que no es verdaderamente una solución, reconocimiento que le permitirá un cambio en su posición respecto del tratamiento, implicándose en el mismo, o decidir su inicio. Es preciso tener presente que pueden presentarse fases agudas durante el mismo, en las que puede ser necesaria una intervención médica 0 , incluso, la hospitalización si la gravedad de la paciente lo requiere.

\section{Alimentación}

La anorexia es la máxima ilustración de que el alimento es más que la mera aportación de nutrientes. En nuestra cultura occidental, impregnada por la religión cristiana, tenemos un buen exponente del significado simbólico que puede tener la comida. En la Eucaristía "la ingesta del cuerpo y de la sangre de Jesucristo bajo la forma del pan y del vino", por efecto de la transustanciación, ha constituido desde el momento histórico de su instauración e institución, un ejemplo altamente significativo de cómo el pan y el vino dejan de ser pan y vino para convertirse, para los creyentes cristianos, en la presencia espiritual y corporal del hijo de Dios. Es decir, para ellos, ingredientes propios de la alimentación dejan de serlo, adquiriendo una dimensión espiritual trascendente. En la anorexia la comida deja de ser alimento y nutrición para convertirse en un objeto que debe controlarse para poder sobrevivir.

La comida no es tan solo un acto mediante el cual las personas nos nutrimos, sino también un medio de comunicación, como bien sabemos todos y sobre lo cual ha profundizado Roland Barthes (1961). Alimentarse es una actividad muy compleja que debemos ubicar en diferentes niveles de experiencia. Tal como expresa Freud en "Tres ensayos sobre la teoría sexual" (1905) el objeto oral por excelencia, la comida, presenta distintos niveles de significado: por un lado encontramos el nivel más evidente que responde a la necesidad biológica de supervivencia, pero para el sujeto humano la comida no se reduce nunca a ella, puesto que el acto de comer tiene un papel de la máxima importancia en la dimensión de las relaciones de los seres humanos entre sí. La comida es el primer don que el sujeto recibe de manos del otro, y es por ello que lleva añadida siempre un valor simbólico y, en consecuencia, entra en juego la dimensión de la relación con el otro. Freud lo explica claramente al exponer que un niño, cuando se orienta hacia el pecho de la madre, continúa 
su experiencia de satisfacción más allá de sus necesidades y demandas nutritivas. Por ello, la comida satisface las necesidades nutritivas, pero sin agotar su significación en ellas. Se trata de una experiencia muy compleja que comporta una dimensión de identificación de la comida con el afecto, la amistad, la dependencia y la seguridad emocional. La persona anoréxica cree controlar la comida cuando, en realidad, actúa dominada por la necesidad de controlar la relación con el otro a través de la comida.

\section{8.- Cuerpo}

El sujeto anoréxico no quiere vivir en su cuerpo, lo rechaza profundamente mediante un gran "no" dirigido a éste. Un no que, a menudo, no puede formular en otros momentos de su vida. ¡Un no imposible de pronunciar en tantas situaciones cotidianas! El cuerpo es el único ámbito en el que él sí puede afirmarse y controlar. Controlar la necesidad de algo o de alguien, de sensaciones, de deseos... y de vida; puesto que, aunque parezca paradójico, para el anoréxico, la no vida del cuerpo garantiza la vida psíquica. Digo esto porque, de acuerdo con mi experiencia clínica, para la persona anoréxica controlar el apetito y desoír las necesidades corporales es algo que le otorga una sensación de poder, de euforia, que le hace sentirse fuerte y poderoso aun cuando su cuerpo presente indudables y patéticos signos de debilidad.

Es precisamente esta vivencia de fortaleza lo que hace difícil ayudar a la persona anoréxica. Ésta no desea un cuerpo que no siente como suyo, al que vive como un añadido, una prótesis de carne que ansía hacer desaparecer. Aunque la visión de ella misma que le ofrece el espejo es la objetiva y compartida por los que la rodean, ella se ve horriblemente obesa y cree, a pies juntillas, que ésta es su verdadera realidad corporal. A pesar de la insistencia por parte de quienes la rodean sobre la imagen real de su cuerpo, nada ni nadie es capaz de hacerle cuestionar su propia percepción a la que se aferra y sostiene como única verdad. Su más profundo anhelo es deshacerse de ese cuerpo que vive como extraño e indeseable. En algunos casos, su vivencia es la de un cuerpo del que su madre se ha apropiado, en otros, de un cuerpo que hizo sentir placer a aquel hombre o chico que abusó de ella, sin que tal situación traumática no le impidiera sentir un cierto gozo involuntario en el abuso; y es de tal apropiación por parte de la madre y por parte del abusador, de esas palabras, de esas manos sobre su cuerpo, de ese goce indeseado, lo que ha de expulsar de su carne a la vez que lucha por encontrar un cuerpo perfecto, puro y etéreo sin sensaciones de ninguna clase y sin dolor ni sufrimiento. La persona anoréxica siente la necesidad de construir un cuerpo perfecto, ideal y preservado del tiempo y de las relaciones. Un cuerpo que no sienta el terrible vacío del desvalimiento y de la soledad. 
En algunos casos de anorexia podemos descubrir, con el tiempo, un abuso sexual en la infancia que no ha sido mentalizado. En este caso el cuerpo es vivido como algo sucio, asqueroso, una carne de la que el sujeto debe deshacerse. El cuerpo lleva la huella de la presencia de otro que lo había utilizado, que lo convirtió en un objeto para su uso sexual, que lo manchó despertándole sensaciones sexuales odiosas y placenteras a la vez. La negativa a comer cumple simbólicamente la doble función de no aceptar la intrusión del otro y, a la vez, de intentar liberarse de esa carne sucia y manchada. El control de la ingesta es un intento desesperado por sujetar, en la actualidad, ya que no pudo ser en el pasado, las riendas de su vida y no volver a vivir el descontrol con el consiguiente caos mental y físico que supuso el abuso sexual. A la vez, un mecanismo para borrar el cuerpo objeto del abuso sexual e inhibir una sexualidad manchada.

\section{9.- SOFIA}

La primera vez que vi a Sofía estaba muy por debajo del peso que le correspondía y hacía tiempo que no tenía la menstruación, debido a lo cual su doctora aconsejaba una hospitalización. Era una chica de 20 años, alta, enfundada en diversas capas de ropa deportiva de las que salían unas manos largas y huesudas; cara alargada, la boca fina y unos grandes ojos marrones de opaca mirada. El pelo corto y escaso. Toda ella irradiaba un halo de desvalimiento e impotencia. "Soy anoréxica" fueron unas de sus primeras palabras, a las que siguieron "no quiero que me ingresen una vez más". Llevaba años estudiando ingeniería, pero los repetidos ingresos hospitalarios a causa de la anorexia habían lentificado sus progresos académicos. Vivía con su madre, divorciada del padre, desde hacía 7 años. A los 14 años fue ingresada por primera vez en un centro para el tratamiento de su anorexia, al que se sumaron posteriormente dos ingresos más. En ellos el tratamiento consistía en un control estricto, con incentivos de premios y castigos, de su régimen alimentario, del peso, a lo que se añadían sesiones de psicoterapia de grupo; aunque Sofía cumplía dócilmente con todo ello, cuando dejaba el centro volvía a adelgazar peligrosamente. Le comenté que si era tan imperiosa la necesidad de controlar la comida debía tener un motivo poderoso para hacerlo, habida cuenta de las consecuencias que le comportaba, y que en nuestra relación podíamos intentar entenderlo.

Dada la precariedad de su estado y el consejo de hospitalización por parte de su doctora le propuse que si ésta y ella lo aceptaban podíamos instaurar un régimen de tres entrevistas semanales durante un mes, y que, si en este tiempo ella continuaba con el mismo peso o menor, entonces sería inevitable recurrir a la hospitalización. Tanto la doctora, como ella, aceptaron la propuesta y, como dado que se produjo un ligero incremento de peso, no hubo 
necesidad de hospitalización. Sofía y yo comenzamos un trabajo terapéutico, iniciando con ello el desarrollo de un proceso largo y a veces muy difícil durante el cual ambas tuvimos que buscar fórmulas nuevas para resolver las complejas situaciones que se fueron presentando a lo largo del mismo.

Podríamos referirnos a diversos aspectos del proceso terapéutico de Sofía, pero he escogido dos que me parecen especialmente relevantes y que valoro como valiosos que nos ayudan a reflexionar sobre los problemas referentes a la alimentación. Centrarnos en algunos aspectos concretos puede darnos una visión sesgada del tratamiento y del proceso que siguió Sofía, pero nos permite focalizar nuestra atención sobre la evolución de dos temáticas importantes en esta patología.

Antes, pero, me permitiré hacer unas puntualizaciones. Tal como le comenté a ella, la persona que controla la ingesta hasta poner en peligro la propia vida debe tener motivos muy poderosos para ello puesto que atenta de forma premeditada contra la propia supervivencia. Por ello, durante el proceso terapéutico no le hice nunca reproches sobre lo que comía o dejaba de comer ni llevé control de sus ingestas; solamente en contadas ocasiones creí oportuno interesarme por sus comidas, en situaciones en los que una situación conflictiva repercutía en una pérdida considerable de peso. Evidentemente el tema de la comida estaba presente, y muy presente, pero el problema no consistía en comer-no comer; la dificultad residía en algún lugar de su interior, en algún rincón de la relación de ella consigo misma y con los demás. Y su actitud frente a la alimentación nos hablaba de ello, de algo que no conocíamos ni ella ni yo y que asomaba la cabeza, de forma muy peligrosa, bajo la forma de la no alimentación.

En su sentimiento interno, Sofía, no tenía nombre. Ella se sentía a si misma solo como un diagnóstico que la identificaba: "soy anoréxica", decía, pero, "tú, ¿cómo te llamas?" le pregunté. Quedó asombrada ante mi pregunta, porque creo que ella se definía simplemente mediante una patología que suplantaba su identidad, con la cual enmascaraba su sentimiento íntimo de sí misma. Una careta con la cual mostrarse y moverse en la vida. Vivirse como anoréxica le ahorraba tener que pensar en ella y en sus sufrimientos, a la vez que le proporcionaba un estatus social: el de enferma que recubría todos los ámbitos de su ser. Ser estigmatizada por diversos profesionales mediante el diagnóstico de anoréxica en su recorrido durante años por diversas instituciones en las que el tratamiento de esta patología se fundamentaba básicamente en centrar la problemática de los pacientes en la importancia del peso corporal, había calado en ella la seguridad con que se adhería a su adquirida identidad de anoréxica. Ésta le ahorraba responsabilizarse de su propia vida y de su salud, otros lo hacían por ella, puesto que era tan solo una enferma. 
Por ello, como elemento primordial para que pudiera apropiarse de su proceso terapéutico, en los primeros tiempos de nuestro encuentro abordamos el significado que le otorgaba el ubicarse solo como anoréxica, a fin de que lograra recuperar su identidad como Sofía, una joven con una historia particular, unas inquietudes propias junto con unas peculiaridades que le permitían reconocerse a sí misma como una persona única. En este período ella visitó una exposición de fotografía sobre cuerpos anoréxicos, lo cual favoreció el diálogo terapéutico respecto a las diferencias subjetivas y corporales entre personas que padecían esta problemática. El hecho de recuperar su nombre, Sofía, y dejar de definirse exclusivamente como anoréxica, le permitió empezar a hablar sobre diversas facetas de su vida no reducidos al tema de la comida.

\section{1.-Muerte}

Uno de los aspectos que más me han impactado en el tratamiento de Sofía, y en general en las pacientes anoréxicas que he asistido, es el de que ellas no creían que llegarían a morir si no se alimentaban. Sofía sabía racionalmente que es así, pero en su interior no existía la relación entre no comer y morir. No comer era la única forma que había encontrado para borrar ese cuerpo que vivía como ajeno. Parecía como si la noción de muerte no tuviera cabida en su mente; en todo caso no la tenía integrada como resultado posible de su comportamiento. Ello constituye un grave problema en el tratamiento de las personas anoréxicas, puesto que una forma que tenemos los humanos para eliminar, evitar o modificar acciones o conductas que puedan sernos perjudiciales es porque ponen en peligro nuestra vida, pero para Sofía no comer, en su mundo interno, no le hacía correr ese riesgo. Ella había escindido de su psiquismo la relación entre no alimentarse y la enfermedad e incluso la muerte. Para ella, en su sentir subjetivo, la muerte no existía con lo cual no comer no implicaba morir.

En los momentos en que le decía que no comer o hacerlo muy escasamente podía provocar su muerte, me respondía: "si", permanecía silenciosa durante unos momentos para finalmente añadir: "pero yo no me creo que pueda morir. Lo entiendo, entiendo lo que me dices, pero no me lo creo. Dentro de mi hay alguna cosa que me dice que no". Durante tiempo yo estuve dudando sobre si la noción de muerte, de la muerte propia, no se había inscrito en su psiquismo, si la negaba o bien era una parte escindida de su conocimiento, tal como creo, según mi frecuente experiencia clínica.

En un intento desesperado de preservar algunas de sus pertenencias personales más preciadas, como zapatos y vestidos, del envejecimiento y con él de la desaparición, del desgaste que supone el uso, de las posibles manchas, roturas y estropicios, las mantenía guardadas en un armario, sin utilizarlas y solo inspeccionándolas de vez en cuando para 
asegurarse que todavía permanecían intactas al paso del tiempo. Ello le producía una tranquilidad sosegada tan diferente a la angustia que sintió cuando se encontró un objeto, una silla que había pertenecido a su tía-abuela, con las piernas raídas por la carcoma. Diríase que, para Sofía, en muchas ocasiones, el objeto adquiría las características emocionales de la persona a la que estaba asociado siendo a veces más fácil la relación con éste que con su propietaria.

El tiempo, este gran escultor como afirmaba Marguerite Yourcenar (1983), era una presencia terrible para Sofía. El tiempo modela los cuerpos, modifica las relaciones, domina nuestro paso por la vida, condiciona la duración de los objetos, pone límite a toda existencia. Cada vez que la tiranía temporal se manifestaba, ya fuera en un objeto apreciado que se estropeaba por el uso o una persona querida que envejeciera, Sofía lo vivía con una fuerte angustia. Frente al sufrimiento que le producían los efectos de la temporalidad encontró en el mecanismo de la escisión psíquica un potente aliado. No se sentía dominada por el tiempo, sino sentía que era ella la que podía dominarlo y creía poder ejercer un control sobre todo lo que le sucedía. En su fuero interno ella era la que controlaba y decidía.

La muerte es la ineludible consecuencia del paso del tiempo a la vez que el límite más innegable de nuestra existencia. Sofía no podía, por un lado, soportar el dominio de esta feroz tiranía a la que todos los humanos por nuestra finitud estamos sometidos, y, por otro, la constancia de nuestra individualidad que la muerte impone, morimos solos, la muerte es un acto individual. Sofía, mediante su rechazo de todo alimento buscaba encontrar una subjetividad propia, individual e íntima en la soledad, no en la vida sino en la muerte.

Hija de un padre poco presente en la familia, Sofía lo era todo para la madre. Era la confidente que escuchaba sus reiteradas quejas sobre su desgraciada vida y a la que deseaba tener constantemente a su lado para asegurarse que comiera, a la que le pedía que comiera para ella, el único goce de su vida, la sola ilusión para vivir. Sofía lo era todo para esta madre que anteponía las mínimas necesidades y deseos de los hijos a los propios. Una vida, la de la madre, que parecía no existir por sí misma, que se alimentaba emocionalmente de la de sus hijos. Fue interesante constatar como a raíz del aumento de la capacidad de Sofía para sentir y desarrollar su propia subjetividad, la madre fue interesándose por su propia vida y consiguió construir una nueva relación de pareja.

\section{2.- Cuerpo}

Sofía vivía su cuerpo como una pesada carga, como algo incómodo, molesto, desdeñable, horrible. Su cuerpo había de desaparecer. ¿Pero, en qué cuerpo vivía ella? ¿Un cuerpo que era suyo? ¿O no lo era? Sofía tenía muy presente la frase que su madre le decía reiteradas 
veces: "come para mí", es decir que ella comía, pero quien, según la frase, recibía el alimento era la madre. Siendo así: ¿de quién era el cuerpo? Escuchar esta frase suponía una verdadera tortura para Sofía hasta el punto de que no podía oírla sin sentir una profunda irritación y rabia hacia la madre.

Sofía no había podido llegar a tener una vivencia de su cuerpo como algo totalmente propio, como una entidad que le perteneciera absolutamente. Por ello, en un intento de sobreponerse a esta apropiación de su cuerpo por parte de la madre, había escindido las vivencias sensocorporales y emocionales para refugiarse en una pseudorealidad que ella pretendía ser únicamente racional. Para ella la realidad de su vida se centraba tan solo en sus ideas y pensamientos, e identificándose con ellos aniquilaba toda sensación que proviniera del cuerpo. Sofía se vivía como una enorme mente sin cuerpo, el cuerpo carecía de realidad en su vivir, era una molestia, un objeto físico que la remetía a su materialidad con lo cual se le hacía insoportable y con el que luchaba para desprenderse de él. A mi pregunta sobre "¿tu quién eres?" me respondió "mi cabeza", y "¿el cuerpo?" volví a preguntar, a lo que siguió un largo silencio sin que ella supiera dar ninguna respuesta. Vivir en su "cabeza", reducir su corporalidad al pensamiento, le concedía la ilusión de vivir sin cuerpo en un intento desesperado de controlar su vida.

Por largo tiempo durante el tratamiento parecían no existir las sensaciones corporales ni los sentimientos. No es que careciera en absoluto de estos últimos, pero los vivía como fruto de su racionalidad. Respecto a las sensaciones corporales parecían serle desconocidas, como si viviera en un cuerpo inerte, sin vida. Su acuciante anhelo de controlar su cuerpo, en virtud de lo cual rechazaba cualquier sensación que proviniera de él, fue el origen de un mecanismo tan contundente en la negación de las emociones que éstas llegaron a ser inapreciables para ella misma. Durante el proceso terapéutico las emociones iban apareciendo sutilmente, progresivamente, cosa que le provocaba un fuerte estado de desazón e inquietud. Empezó a sentir algunas sensaciones de malestar, especialmente en la zona del estómago, las cuales la desorientaban profundamente y que atribuía a una pequeña indigestión. Con el tiempo pudo reconocer y aceptar la incidencia de algunos acontecimientos exteriores en sus molestias corporales. Su cuerpo resurgía, volvía a tener vida, a manifestarse con molestias, dolores que se escapaban de su control racional, revivía y lo hacía con un lenguaje que le era inquietante y desconocido, pero por encima de todo, incontrolable.

Sofía vivía en un estado de pánico profundo que afloraba en los momentos en los que no podía controlar cualquier cosa de su alrededor. El control de la comida, de las situaciones, de las relaciones... el control del número que marcaba la báscula. Un número que no podía 
oscilar, que debía permanecer inmóvil señalando una cifra determinada, bajo el riesgo de hacer sucumbir su universo emocional. Un número que ella dictaminaba cada vez más bajo hasta...no se sabía cuándo. Si el peso subía, ni que fuera marcando unos pocos gramos de más, el pánico se le disparaba puesto que, según su sentir, si no había podido controlar la báscula ésta podía subir y subir de numeración sin límite y ella se volvería monstruosamente gorda.

Sofía, que no había podido detener la invasión de su espacio vital por parte de su madre, que dependía de la mirada de ésta, de su opinión, de sus estados de ánimo, de su dolor que ella vivía como propio; pero sí que, en cambio, era capaz de decir no a las necesidades de su cuerpo, a una comida que no había de dejar entrar en él. El sentimiento de omnipresencia con que Sofía vivía a su madre penetraba en los rincones más íntimos de su ser adueñándose de ellos, frente a lo que ella se revelaba ante la vivencia de esta intrusión mediante un gran "no". Un gran "no" dirigido a esta subjetividad ajena que vivía en ella como una hiedra que crecía y se enraizaba en ella sin dejarle lugar para la propia vida. Sofía era una rebelde con causa y, a la vez, una luchadora por su independencia, para reencontrar un universo propio que intentaba hallar al vaciarse de una presencia ajena.

Un cuerpo que era compartido por otro del cual no podía separarse sin matarlo, como siameses sin posibilidad de vida individual. "Tenemos un pulmón. Las dos respiramos por el mismo pulmón". Separarse del otro era dejar de respirar, era la muerte, la verdadera muerte. Una intimidad y dependencia que no quería ni podía sentir; en contrapartida, controlar la comida la hacía sentirse fuerte y poderosa, eufórica, viva. Ella era la que controlaba, la que no dependía de nadie, la que no necesitaba a nadie.

La anorexia para Sofía era un intento, mortífero, pero un recurso con el que pretendía conseguir desprenderse del otro introyectado que atenazaba y aprisionaba su vida. El proceso terapéutico con ella fue básicamente ayudarla mediante la escucha atenta y cálida de su sufrimiento, junto con el diálogo respetuoso entre ambas intentando comprendernos mutuamente. Tratar de que pudiéramos entender los motivos que la impulsaban a tener una relación tan funesta con la alimentación, ofrecerle un marco terapéutico seguro pero no inmóvil, confiar en la capacidad de responsabilizarse de su propia vida, valorar su subjetividad de persona singular, distinta y separada de la terapeuta pero reconocida por ella en sus capacidades y peculiaridades para permitirle adquirir su propia identidad, utilizar la capacidad creativa de ambas junto con el sentido común para sortear los imprevistos, interferencias y dificultades en el proceso terapéutico.

Todo ello propició que fuera reconociendo y apropiándose poco a poco de su propia subjetividad, que superara la disociación con sus sensaciones y sentimientos para hacer 
también de ellos, junto a la racionalidad, elementos de conocimiento propio y a la vez de guía en sus decisiones, lo que le permitió vivir con una cierta comodidad en su cuerpo.

A mi entender, es fundamental para el paciente anoréxico, aunque, como apunta Joan Coderch (2010) podríamos generalizarlo a todos, la confianza del paciente y del terapeuta para que, a partir de las nuevas experiencias vivenciales, creadas en su relación y las de su vida en su contexto(s), él pueda elaborar nuevas formas de gestionar sus conflictos en sus relaciones y consigo mismo. El soporte de la presencia afectuosa, firme y cálida del terapeuta es lo que permitirá al paciente encontrar nuevas formas de vivir la necesidad que tiene de sentirse querido y respetado, y percibir en el terapeuta una voluntad de acompañarle desde un lugar, distinto al suyo pero próximo, en el nuevo camino que se ha iniciado a través de la creativa interacción entre ambos.

\section{REFERENCIAS}

ALESSI, N.E., KRAHN, D., BREHM, D., WITTEKINDT, J. (1989). Prepubertal anorexia nervosa and major depressive disorder. J. Am. Acad. Child Adolesc. Psychiatry, 28 (3), 380384 .

BARTHES, R. (1961). Pour une phycho-sociologie de l'alimentation contemporaine, Annales, Economies, Sociétés, Civilisations, $\mathrm{n}^{\circ}$ 5, pp. 977-986.

CAPARRÓS, N., SANFELIÚ, I. (1997). La anorexia: una locura del cuerpo. Madrid: Ed. Biblioteca nueva.

CODERCH, J. (2010). La práctica de la psicoterapia relacional. Madrid, Ágora relacional.

CODERCH, J. (Coord.). (2018). Las experiencias terapéuticas en el proceso psicoanalítico. Madrid, Ágora relacional.

COSENZA, D. (2008). El muro de la anorexia, Madrid: Gredos (2013).

FREUD, S. (1905). «Tres ensayos sobre la teoría sexual». Obras Completas. Tomo II, Madrid, Biblioteca Nueva. (1981)

FRIEDLANDER, M. L. y SIEGEL, S.M. (1990). Separation-individuation difficulties and cognitive-behavioral indicators of eating disorders among college woman. Journal of Counseling Psychology, 37 (1), 74-78.

GEIST, R. A. (1989). Self psychological reflections on the origins of eating disorders. Journal of the American Academy of Psychoanalysis, 17 (1), 5-27.

KAFKA . F., (1924). Un artista del hambre. Madrid, Casimiro libros, 2011. 
KRAEMER, H. y SPRENGER, J., (1486). El martillo de las brujas. Para golpear a las brujas y a sus herejías con poderosa maza. Madrid, Ed. Felmar, 1976.

LACAN, J. (1949). El estadio del espejo como formador de la función del yo tal como se nos revela en la experiencia psicoanalítica. En Escritos 1, Siglo XXI Editores, 1984.

TOMAS DE AQUINO, S. Suma de Teológica X. Tratado de la templanza. Tratado de la profecía. Tratado de los distintos géneros de vida y estados de perfección. Edición bilingüe. Biblioteca de autores cristianos. Madrid 2016.

RAIMBAULT, G. y ELIACHEFF, C. (1991). Las indomables: Figuras de la anorexia. Buenos Aires: Nueva visión.

SARTRE, J.-P. (1943). L'Être et le Néant. Essai d'ontologie phénoménologique. Llibrerie Gallimard, Paris. (1994)

THIEL, A., BROOKS, A., OHLMEIER, M., JACOBY, G. y SCHÜBLER, G.. (1995). ObsessiveCompulsive Disorder Among Patients with Anorexia Nervosa and Bulimia Nervosa. Am J Psychiatry, 152, 72-75.

TREASURE, J., SMITH, G., CRANE, A. (2007). Los trastornos alimentarios. Guía para cuidar de un ser querido. Ed. Desclée de Brouwer. Bilbao. 2011

WALTERS, E., KENDLER, K. (1995). Anorexia Nervosa and Anorexic-Like Syndromes in a Population-Based Female Twin Sample. Am J. Pschiatry, 152, 64-71

YOURCENAR, M. (1983). El tiempo, gran escultor. Madrid, Alfaguara, 1992

WINNICOTT, D. W. (1987a). Traducción castellana: Los bebés y sus madres Barcelona: Paidos, 1998.

WINNICOTT, D.W. (1993). Traducción castellana: Conversando con los padres. Aciertos y errores en la crianza de los hijos. Barcelona: Paidos, 1993

Original recibido con fecha: 10/9/2019 Revisado: 30/og/2019 Aceptado: 30/09/2019 